\title{
С.О. Долгих
}

\section{КАЗАЧЕСТВО В КОНТЕКСТЕ ИСТОРИИ ЛОКАЛЬНЫХ КОНФЛИКТОВ КОНЦА ХХ ВЕКА}

\begin{abstract}
Проанализирована проблема историографии истории казачества. В научный оборот впервые вводятся новые источники, позволяющие выявить портретную специфику современного «сегмента» казачества в общей панораме движения военного добровольчества. Это воспоминания участников добровольческого движения. В условиях крушения СССР и деидеологизации общественных движений и инициатив добровольцы из России - казаки в целом придерживались программных установок, нацеленных на защиту православного населения за пределами Российской Федерации.

Ключевые слова: казаки; добровольчество; Приднестровье; Босния; Абхазия; вооруженный конфликт.
\end{abstract}

Казачество, явление сугубо российское, представляет собой формировавшуюся на протяжении веков структуру сословной системы российского дореволюционного общества со специфическими социокультурными характеристиками, политической культурой (или ее отсутствием). Мировая история не зафиксировала сопоставимых по экзотике, колориту, а подчас и одиозности образа явления - аналога казачеству. Казачество дореволюционной России представляло собой военизированную и достаточно многочисленную социальную группу общества с его преимущественно деструктивной ролью в Смутное время и периоды масштабных крестьянских волнений. Воздействие на казачество государственной политики по привлечению к защите рубежей государства общеизвестно. Трансформация внутреннего устройства казачьего сословия [1. C. 25], усиленно проводившаяся в правление Петра I и Екатерины II, превратила казачество в одну из опор центральной власти. Это можно проследить на примере войн начала XVIII в., в ходе которых казачество проявило качества доблести и верности Отечеству. Такая патриотическая модель сознания до сих пор составляет ментальную основу мировоззрения российских казаков.

Основные препятствия для научных исследований истории казачества связаны, на наш взгляд, с перипетиями исторической памяти о событиях и процессах $\mathrm{XX}$ в., а также с императивом сохранения культурного наследия. Открытым остается и вопрос о дальнейшей судьбе казачества. Эти размышления гуманитариев дополняют список малоизученных и противоречивых версий происхождения казачества. В массовом сознании закреплен миф-стереотип о казачестве, сформированный в XX в. Сословие является носителем культурного пласта со специфическими патриархальными традициями, своеобразием обычаев служилого военного сословия, включая фольклор. Исторический образ казачества далеко не всегда положителен, и весьма распространены сатирические и вульгаризированные его варианты.

Новой вехой истории казачества стал поворотный для него конец $\mathrm{XX}$ в. С началом перестройки правительство признало акт репрессий по отношению к каза- честву. Появилась возможность не только социальной реабилитации казаков, но и шанс заглянуть вглубь истории. Перед казаками возникла перспектива обрести субъективность на фоне того, что в силу исторических обстоятельств казачество оказалось территориально разделенным. Постсоветская история казачества была не менее драматична и в ситуациях чрезвычайности для судеб Отечества в определенном смысле отмечена примерами самоотверженности. Череда конфликтов на обширном постсоветском пространстве тому подтверждение. Казачество проявило свою пассионарность, приняв участие в конфликтах, нередко составляя основную часть добровольческого движения. Примером служат события в Приднестровье, Абхазии, Карабахе.

Из исследований, посвященных проблемам истории казачества постсоветского времени, выделим работу Т.В. Таболиной. Автор специализируется на истории русской эмиграции, но в зоне внимания находится и казачество [2. С. 29]. Таболина изучала попытки казаков обрести политическую, социальную, культурную субъективность 90-х гг. ХХ в. Она анализирует проекты союза казачьих общин, акцентируя внимание на том, что в начале последнего десятилетия прошлого века основной установкой казачества было стремление реализоваться в Российском государстве, обрести административный и правовой статус, сопоставимый с республиками, сформированными по этническому принципу, создать административные структуры. Аналогами предполагаемых структур предлагалось сделать казачий круг, «воинства» избираемых атаманов. К категории акций, квалифицируемых как политическая деятельность, относятся совместные проекты с государством. Это, например, инициатива и попытки охраны границы между Россией и Казахстаном, прекращенные по договоренности внешнеполитических ведомств государств.

Д.Н. Соловьев [3] рассматривает казачество с позиций его возможностей мобилизационного ресурса. Его версия может трактоваться как взгляд на казачество с точки зрения экстренного резерва вооруженных сил и парамилитаристких соединений на случай вызовов национальной безопасности России. Соловьев исследо- 
вал аспект экономической рентабельности данного резерва, проанализировал исторический опыт использования казачества государством. В поле пристального внимания диссертанта оказались система подготовки казаков и система управления казачеством [3. С. 650]. Статьи О.В. Рвачевой, сосредоточившейся на этнологических и социальных ракурсах темы, посвящены попыткам институализации казачества и взаимодействию с другими этносоциальными группами [4. С. 43-51; 5. С. $143-147 ; 6$. С. 98-101]

Однако казачество, точнее та его часть, которая апеллирует к традициям и усматривает свою миссию на поприще военно-политическом, не рассматривается. Факты и свидетельства участия казаков в конфликтах конца XX в. подтверждаются воспоминаниями ветеранов войн, материалами как отечественных, так и зарубежных СМИ. Именно материалы СМИ составляют «остов» источников по теме. Сложность работы с источниками данного рода состоит в том, что их материал в большинстве случаев мифологичен.

Современная методология по работе с такими источниками встраивается в сосредоточение усилий историков на аргументации, с тем, чтобы избавиться от легендарной, мифилогизированной части, а также на опровержении устойчивых мифов о казачестве. В целом большинство исследований, опубликованных в СМИ, не выдерживает серьезной критики. В то же время СМИ задают информационную повестку освещения взаимодействия казачества с остальным обществом и государством.

Одним из исследований, непосредственно касающихся военной составляющей деятельности казачества, стала работа М.А. Малкиной, базирующаяся на материалах архива Кубанского казачьего войска. Автор отобразил схему взаимодействия структур казачества с непризнанными государственными формированиями, правительствами Молдовы, Грузии и РФ. По данным М.А. Малкиной, в Приднестровье воевало 187, а в Абхазии - около 1500 казаков [7. С. 23].

В имеющихся работах историков-специалистов, несмотря на их фундаментальный характер, отсутствуют отсылки к такому источнику, как мемуары, а они-то порой являются наиболее аутентичным источником по теме внутреннего устройства казацких подразделений и взаимоотношения казачества с остальным миром в рассматриваемый период. Так, например, есть материалы и свидетельства участия казаков в Боснийской войне 1992-1995 гг., содержащиеся в воспоминаниях. Они дают редкую возможность проследить организационную структуру казачьих формирований, а также их взаимоотношения с окружающим населением и другими, неказацкими русскими подразделениями.

На основании такого материала можно упоминать о казачьих подразделениях Республики Сербской во время Боснийской войны. По воспоминаниям Игоря Гиркина, прибытие казаков в Боснию датируется в конце декабря 1992 г. Он свидетельствует о привиле- гированном положении казачества по сравнению с другими добровольцами. Об амбициях, возможно оправданных, свидетельствует факт, что казаки сразу начали формировать отдельное подразделение. «Приезжая в Боснию, вообще не ожидали, что нам будут скольконибудь платить (тем не менее, мы получали по 100-150 Deutsche Mark в месяц), а казаки договорились заранее о 350 марках. Кроме того, мы ожидали, что казаки каким-то боком вольются к нам в отряд. Но вербовщик, некий “Александр Загребов” (по собственному признанию, бывший лейтенант-особист Советской Армии), смотрел на нас иначе, как на неких “конкурентов”, что привело впоследствии к целой череде столкновений и неурядиц». Гиркин фиксирует присутствие нескольких подразделениях казаков: «Тем более что были и другие отряды - 1-й РДО ${ }^{1}$ в г. Требине, 1, 2 и 3 сводные казачьи сотни в Вышеграде, еще действует 3-й РДО под Сараево» [8. С. 47].

По воспоминаниям Олега Валецкого, казаки появились в Боснии в конце 1992 - начале 1993 г. и были там до февраля 1993 г. Согласно приводимой им статистике, первая группа состояла из 50 казаков. Начальная акция, в которой участвовал казачий отряд вместе с бойцами 2-го РДО в районе Вышеграда, означала контрудар под сербским городом Руде. До этого боснийские подразделения захватили сербский город, в результате чего образовался клин на территории сербов. Задачей отряда было выбить мусульман из населенного пункта. «Сербское командование послало на помощь своих “интервентов” из Вышеградской бригады, насчитывающей, кроме десятка-другого сербов, и тридцать человек казаков, а также добровольцев 2-го РДО. Казаки под командованием Александра Загребова были главной ударной силой. Они разделились на две части, одна пошла по дороге, разбирая завалы в тоннелях под прикрытием шедшего с ними БОВ (югославский вариант советской бронированной разведывательно-дозорной машины БРДМ-2), за которым шел “троцевац” (самоходная колесная зенитная установка с тремя автоматическими пушками калибра 20 миллиметров). В БОВе, как и в “троцевце”, экипажи были казачьи. Вторая часть казаков пошла по горным тропам, дабы соединиться вместе уже перед последним селом, около которого и шла передовая линия сербской обороны» [9. С. 10]. Итогом операции стало то, что боснийские мусульмане удерживать позиции не стали и вернулись на прежние места дислокации.

Отдельным сюжетом анализа предстает взаимодействие казачества и 2-го РДО. Валецкий повествует о конфликте между командиром казачьего отряда Александром Загребовым с бойцами 2-го РДО. Причина конфликта не называется, но указывается факт, что в среде сербского командования казаки «уважались»: завоевали приоритетное к себе отношение. Все закончилось покушением нескольких добровольцев на Загребова, что грозило применением казаками оружия. Валецкий действия казаков оценивает так: «Воевали 
казаки хорошо, и зря сербское командование их тогда толком не использовало». Особой сложностью отличались ночные рейды. «Подобные действия могла предпринимать только отработанная группа, ибо любое изменение плана означало потерю связи и угрозу открытия огня по своим. Так что уже одно то, что казаки из Вышеграда ходили в ночные рейды, составляет им честь. Рейды - дело опасное. Под Буяком казачья группа, возвращаясь на базу неапробированным путем, натолкнулась на группу мусульман, следовавших по старому маршруту. Казаки тогда первые с близкого расстояния открыли огонь, нанеся противнику урон, но те все же успели уйти» [9. С. 12].

Примечательно, что Валецкий упоминал факт использования казаками некоторых видов боевых машин. При взятии села Твыртковичи казаки отрабатывали захват населенного пункта после тренировки на своей базе. Подсчитать потери казаков за период боевых действий не представляется возможным. Казаки участвовали и в действиях, не засвидетельствованных письменно.

Доброволец Михаил Аркадьевич Поликарпов в своей книге исследует историю казачества пристальнее, и этой теме посвящен фрагмент книги [10. С. 167-182]. В предисловии Поликарпов формулирует посыл: «Рассказывая о делах боснийских, мы будем часто произносить слово “доброволец”». Смысл определения он рассматривает двояко. «Иногда мы употребим его для всех русских, приехавших помогать сербам. А иногда - как противопоставление слову “казак”» [Там же. С. 180]. В одном из фрагментов книги Поликарпов описывает путь добровольца под псевдонимом «Ас». Сообщенные сведения, основательный объем информации, касающейся казачества, да и само повествование начинаются с событий в Приднестровье. «В конце марта, прибыв в Тирасполь из Одессы, Саша поразился - ни тебе войны, ни милиции. У штаба приднестровской обороны увидел казаков, точно сошедших со старой картины - в галифе, с лампасами, там и сям были мохнатые папахи, нагайки, золотые погоны. Придя в недоумение, Александр назвался семипалатинским казаком и попросился в казачью часть. Его не взяли» [Там же. С. 103].

Мемуарист описывает акты безумной храбрости казаков. По тексту можно судить о внутренних правилах функционирования вооруженных сил Приднестровья, взаимодействии и взаимоотношениях добровольцев и казаков, отношениях внутри казацкого сообщества, условиях проживания и оснащения, а также мотивировке действий и «информационной повестке» в среде казачества. Ссылаясь на воспоминания Аса, Поликарпов сообщает о реформировании вооруженных сил Приднестровья. «Прежних казаков уже не было - их разогнали, а на базе “диких" формирований создали Черноморское казачье войско, - пишет он. - Тогда Ас вступил в ТСО - территориальный спасательный отряд... Всего в ТСО было около пятидесяти бойцов, среди них и сорокалетний питерец Валерий Власенко, в прошлом - рядовой морпех в Анголе, а в дальнейшем командир РДО-1 в Герцеговине. Командиром был Володя, огромный атлетически сложенный мужчина. Его замом - Виктор, ранее охранявший кого-то из коммунистической номенклатуры Молдавии. ТСО экипировали единой формой местного производства, напоминавшей скорее окрашенную в светло-коричневый и темнозеленый цвета мешковину» [10. С. 120].

В Приднестровье, как явствует из публикаций, были будущие участники событий в Боснийской войне. М. Поликарпов фиксирует время появления на территории бывшей Югославии казаков: «В конце 1991 большая группа русских полегла в боях под Вуковаром, позже около трех десятков казаков воевали в Сербской Краине против хорватов близ городка Смилчич западнее Книна» [Там же. С. 97]. Несколько русских, в том числе и некто Александр Загребов, в конце 1992 г. взялись сколачивать отряды добровольцев и казаков для отправки в Боснию на срок в два месяца по приглашению Вишеградской и Гражданской общин.

Вся информация о казаках-добровольцах поступает двумя путями. Первый состоит в том, что автор «напрямую» делает повествовательные или аналитические заметки о казачестве и казаках. «Косвенный» путь состоит в том, что автор в процессе раскручивания сюжетной линии останавливается на истории отдельных добровольцев, уточняя, что они казаки, и указывая, к какому казачьему войску относятся. Так, выяснилось, что некоторые казаки «приехали как своеобразный залог за деньги, которые сербы отправили в Россию для переброски казаков в Боснию» [Там же. С. 157]. Михаил Аркадьевич вводит исторический ракурс и реконструирует моральный облик донского казачества, пишет о том, что не все поведенческие нормы казаков были приемлемы. Это замечалось за ними и более ста лет назад, как отметил доброволец и корреспондент, участник войн 1876-1878 на Балканах М.В. Максимов, свидетельствовавший, «что именно “инородцы”, подражая в удали и бесшабашности казакам, в основном и портят последним репутацию» [Там же. С. 156]. По мере перемещения «границы дальше к югу “боевитость” осталась у казаков кавказской линии, постоянно находившихся в состоянии войны с горцами. Донцы же, мягко говоря, потеряли тонус» [Там же].

Поликарпов приводит черты ставшего классическим образа казака столетней давности, негативное отношение к остальным русским и даже противопоставление себя остальной массе населения. По его свидетельствам, в казацкой среде популярны альтернативные толкования исторических событий, имея в виду область войска донского. Возможно, данные исторические и культурологические экскурсы не случайны и порождены не сложившимся изначально отношениями.

Сообщая, что в начале 1993 г. приехал 41 человек, Поликарпов, более подробно, чем Валецкий, характеризует личность приведшего группу. Александр Загребов «был вербовщиком, торговцем “живым товаром”, 
но мог и возглавлять казаков в бою, и даже как-то поддерживать среди них дисциплину. Для этого надо быть человеком бесстрастным и бесстрашным». Интересно, что описание совместного боя под Вышеградом отличается от воспоминаний Валецкого. Поликарпов не характеризует сам военный конфликт, он лишь указывает на результат боя, когда взаимоотношения между добровольцами и казаками значительно ухудшились. Он не указывает причину этого и лишь называет факты, некоторые из которых связаны с описанным боем. Накаляли взаимоотношения и бытовые перипетии и изменившееся впоследствии настроение сербов.

Упоминает Михаил Аркадьевич и об отряде казаков в Скелани: в отряд также входили кто-то из «питерских националистов». В начале 1993 г. туда прибыла группа казаков Атаманского полка, нос12 двенадцать человек. Отряд, возглавляемый Александровым, и казакиатаманцы противостояли мусульманскому гарнизону Сребреницы, в составе которого воевала и группа моджахедов азиатского происхождения [10. С. 180]. Материал о казачестве, действовавшем в зонах боевых конфликтов, предоставленный в воспоминаниях Поликарпова, Валецкого, Гиркина, т.е. свидетельствах «из первых уст» участников конфликта, дает представления о фактической картине происходившего.
Подводя итог вышеизложенному, позволю себе ремарки по поводу процесса возрождения казачества как явления. Популярны фольклорные, этнокультурные «достижения», т.е. уникальные образцы культурных амальгам как результата исторических перипетий. В вопросе о возрождении казачества обычно реконструируется внешний облик казаков, мифический, почти штампованный. Истинное же содержание возрождения казачества лежит в восстановлении хозяйственных отношений как основы сословия. Конечно, казачество достаточно консервативная по параметрам уклада, образа жизни структура, и ее основа остается почти неизменной на протяжении длительного времени. Изменяется лишь картина жертв, которые приносит казачество. Это либо людские потери вплоть до полного исчезновения казачьих поселений и областей, либо вульгаризированная трансляция устоев жизни и быта.

Нередко казачество составляет основу добровольчества в локальных конфликтах новейшего времени. Проблема мотивации казачества, их установки на участие в войнах являются актуальной проблемой морального выбора, тенденций социального развития или мировоззрения группы лиц. Без обращения к ней не понять тех, кто понес чудовищные потери в XX в. и все же имеет силу снова взяться за оружие, а также не ответить и на вопрос, чем является военное добровольчество в целом.

\section{СПИСОК СОКРАЩЕНИЙ}

${ }^{1}$ РДО - Русский добровольческий отряд.

\section{ЛИТЕРАТУРА}

1. Бенку И.В. Система казачьего самоуправления с XVIII в. по 1860 г. (на примере Донского, Запорожского и Черноморского казачьих войск) : дис. .... канд. ист. наук. Краснодар, 2005.

2. Таболина Т.В. Казачество на рубеже XXI века: проблемы и возможности. М., 1997.

3. Соловьев Д.Н. Казачество как мобилизационный ресурс российского государства (XV - конец XX века) : дис. ... д-ра ист. наук. СПб., 2011. $650 \mathrm{c}$.

4. Рвачева О.В. Казачьи организации волгоградской области в конце XX начале ХХІ в. // Вестник Волгоградского государственного университета. Серия 4: История. Регионоведение. Международные отношения. 2008. № 1. С. 43-51.

5. Рвачова О.В. Власть и казачество на юге России в конце XX - начале XXI в.: от конфронтации к сотрудничеству // Власть. 2010 . № 10. C. $143-147$.

6. Рвачева О.В. Казачество в современном социокультурном пространстве юга России: проблемы возрождения и взаимодействия с другими народами // Известия Волгоградского государственного технического университета. 2014. № 13. С. 98-101.

7. Малкина М.А. Участие кубанских казаков в региональных конфликтах на постсоветском пространстве (на примере войн в Приднестровье и Абхазии в 1990-е гг.) // Теория и практика общественного развития. 2013. № 12.

8. Гиркин И.В. 2-й Русский Добровольческий Отряд в Боснии 1992-1993 годы // Спецназ России. 1999. № 4 (33).

9. Валецкий О.В. Волки белые. Сербский дневник русского добровольца 1993-1999. M. : Грифон, 2006. C. 288. URL: http://militera.lib.ru/ memo/russian/valetsky_ov01/index.html (дата обращения: 26.02.2016).

10. Поликарпов М.А. Русские волки. М. : Эксмо, 2010. 352 с.

\section{Dolgikh Sergey O., Kazan National Research Technological University (Kazan, Russia). E-mail: d.sergei@hotmail.com}

\section{COSSACKS IN THE HISTORY OF THE LOCAL CONFLICTS IN THE END OF THE XX CENTURY}

Key words: Cossacks; volunteering; Transnistria; Bosnia; Abkhazia; armed conflict.

The aim of the study was to identify the value of source analysis of the latest stage of military volunteers movement with the participation of representatives of the Cossacks. To achieve this goal the following tasks were set: to show the main directions of a Cossacks historiography of the late XX century, to identify and characterize new source material, to point out the agenda of information sources. Research methodology: the author has proceeded from the principles of objectivism and historicism, analysis of the historiography produced in the framework of conceptualistic model. Special historical methods, such as comparative historical, structural functional and chronological problem methods had been applied to understand the role described by the author of the phenomenon of volunteerism and the role of the Cossacks in the era of geopolitical fault. Source base for the study was a new kind of source. It is the memories of participants of the volunteer movement and participants of local conflicts, in this case it is the memories by I. Girkin, M. Polikarpov, and O. Valetsky. This group is introduced into scientific circulation for the first time and allows to reveal the portrait specifics of the current "segment" of the Cossacks in the general panorama of the military volunteers movement. These sources also are able to reveal the socioorganizational aspects of Cossack units. From them we learn the internal organization and management, combat skills, organizational and mobilization capacities. During the conducted research the author came to the following conclusions: in the analysis of historiog- 
raphy the author concludes that at the present stage of study of the Cossacks the following directions dominate in the Humanities: problems of social and political institutionalization, ethnological peculiarities of life and culture, as well as the use and modernization of the historical experience of the Cossacks. One of the problems which were not reflected in the current research is the militaristic aspect of the Cossacks. This type of activity in most of the cases are in the area of media coverage. But the source in most cases is mythological and subjective, and often does not create a full picture. The analysis of such sources as memoirs leads to the following conclusions: the qualitative superiority of the Cossack units on most of the units of the Republic of Serbia. Apart from the fact that the Cossack units were the size of a squadron, unlike the other foreign volunteer units up to platoon, also had a higher professional quality and equipped with combat vehicles, but at the same time was anarchic and had problems with discipline. The dominant motivating setting, in terms of the collapse of the USSR and deideologization of social movements and initiatives, the Cossacks were protecting the Orthodox population on the territory of Russia and outside.

\section{REFERENCES}

1. Benku, I.V. (2005) Sistema kazach'yego samoupravleniya s XVIII v. po 1860 g. (na primere Donskogo, Zaporozhskogo i Chernomorskogo kazach'ikh voysk) [The system of Cossack self-government since the $18^{\text {th }}$ century till 1860 (a case study of the Don, Zaporozhye and the Black Sea Cossack armies)]. History Cand. Diss. Krasnodar.

2. Tabolina, T.V. (1997) Kazachestvo na rubezhe XXI veka: problemy $i$ vozmozhnosti [Cossacks at the turn of the 21 st century: problems and opportunities]. Moscow: Institute of Ethnology and Anthropology RAS.

3. Solovyev, D.N. (2011) Kazachestvo kak mobilizatsionnyy resurs rossiyskogo gosudarstva (XV-konets XX veka) [Cossacks as a mobilization resource of the Russian state (the 15th - late 20th centuries)]. History Dr. Diss. St. Petersburg.

4. Rvacheva, O.V. (2008) Kazach'i organizatsii volgogradskoy oblasti v kontse XX nachale XXI v. [Cossack organizations of Volgograd region in the late 20th - early $21 \mathrm{st}$ centuries]. Vestnik Volgogradskogo gosudarstvennogo universiteta. Seriya 4: Istoriya. Regionovedeniye. Mezhdunarodnyye otnosheniya - Science Journal of Volgograd State University. History. Area Studies. International Relations. 1. pp. $43-51$.

5. Rvachova, O.V. (2010) Vlast' i kazachestvo na yuge Rossii v kontse XX nachale XXI v.: ot konfrontatsii k sotrudnichestvu [Power and the Cossacks in the south of Russia in the late XX beginning of the XXI century: from confrontation to cooperation]. Vlast'. 10. pp. $143-147$.

6. Rvacheva, O.V. (2014) Kazachestvo v sovremennom sotsiokul'turnom prostranstve yuga Rossii: problemy vozrozhdeniya i vzaimodeystviya s drugimi narodami [Cossacks in the modern socio-cultural space of the south of Russia: the problems of revival and interaction with other peoples]. Izvestiya Volgogradskogo gosudarstvennogo tekhnicheskogo universiteta. 13. pp. 98-101.

7. Makhalkina, M.A. (2013) Participation of Kuban Cossacks in the regional conflicts in the post-soviet space (a case study of the wars in Transnistria and Abkhazia in the 1990-s). Teoriya i praktika obshchestvennogo razvitiya - Theory and Practice of Social Development. 12. (In Russian).

8. Girkin, I.V. (1999) 2-y Russkiy Dobrovol'cheskiy Otryad v Bosnii 1992-1993 gody [The 2nd Russian Volunteer Detachment in Bosnia in 1992-1993]. Spetsnaz Rossii. 4(33)

9. Valetskiy, O.V. (2006) Volki belyye. Serbskiy dnevnik russkogo dobrovol'tsa 1993-1999 [White Wolves. Serbian Diary of a Russian Volunteer, 19931999]. Moscow: Grifon. [Online] Available: http://militera.lib.ru/memo/russian/valetsky_ov01/index.html. (Accessed: 26th February 2016).

10. Polikarpov, M.A. (2010) Russkiye volki [Russian Wolves]. Moscow: Eksmo. 